\title{
Reduction of $\beta$-amyloid pathology by celastrol in a transgenic mouse model of Alzheimer's disease
}

\author{
Daniel Paris,', Nowell J Ganey, Vincent Laporte, Nikunj S Patel, David Beaulieu-Abdelahad, Corbin Bachmeier, \\ Amelia March, Ghania Ait-Ghezala, Michael J Mullan
}

\begin{abstract}
Background: $A \beta$ deposits represent a neuropathological hallmark of Alzheimer's disease (AD). Both soluble and insoluble $A \beta$ species are considered to be responsible for initiating the pathological cascade that eventually leads to $A D$. Therefore, the identification of therapeutic approaches that can lower $A \beta$ production or accumulation remains a priority. NF $\kappa B$ has been shown to regulate BACE-1 expression level, the rate limiting enzyme responsible for the production of $A \beta$. We therefore explored whether the known NF $\kappa B$ inhibitor celastrol could represent a suitable compound for decreasing $A \beta$ production and accumulation in vivo.

Methods: The effect of celastrol on amyloid precursor protein (APP) processing, A $\beta$ production and NF $\kappa B$ activation was investigated by western blotting and ELISAs using a cell line overexpressing APP. The impact of celastrol on brain $A \beta$ accumulation was tested in a transgenic mouse model of $A D$ overexpressing the human APP695sw mutation and the presenilin-1 mutation M146L (Tg PS1/APPsw) by immunostaining and ELISAs. An acute treatment with celastrol was investigated by administering celastrol intraperitoneally at a dosage of $1 \mathrm{mg} / \mathrm{Kg}$ in 35 week-old Tg PS1/APPsw for 4 consecutive days. In addition, a chronic treatment (32 days) with celastrol was tested using a matrix-driven delivery pellet system implanted subcutaneously in 5 month-old Tg PS1/APPsw to ensure a continuous daily release of $2.5 \mathrm{mg} / \mathrm{Kg}$ of celastrol.
\end{abstract}

Results: In vitro, celastrol dose dependently prevented $\mathrm{NF} \kappa \mathrm{B}$ activation and inhibited BACE-1 expression. Celastrol potently inhibited $A \beta_{1-40}$ and $A \beta_{1-42}$ production by reducing the $\beta$-cleavage of APP, leading to decreased levels of APP-CTF $\beta$ and APPs $\beta$. In vivo, celastrol appeared to reduce the levels of both soluble and insoluble $A \beta_{1-38}, A \beta_{1-40}$ and $A \beta_{1-42}$. In addition, a reduction in $A \beta$ plaque burden and microglial activation was observed in the brains of $\mathrm{Tg}$ PS1/APPsw following a chronic administration of celastrol.

Conclusions: Overall our data suggest that celastrol is a potent $A \beta$ lowering compound that acts as an indirect BACE-1 inhibitor possibly by regulating BACE-1 expression level via an NF $\kappa$ B dependent mechanism. Additional work is required to determine whether chronic administration of celastrol can be safely achieved with cognitive benefits in a transgenic mouse model of AD.

\section{Background}

Alzheimer's disease (AD) is an ever-increasing health concern among the aging population and is the most common form of dementia affecting more than 25 million individuals worldwide. While the cause of the disease is uncertain, there are two major neuropathological hallmarks present in the brains of AD patients: the extracellular senile plaques and the intracellular neurofibrillary tangles. Neurofibrillary tangles contain

\footnotetext{
* Correspondence: dparis@rfdn.org

The Roskamp Institute, 2040 Whitfield Avenue, Sarasota, FL 34243, USA
}

hyperphosphorylated microtubule-associated protein tau, while senile plaques contain a core of $\beta$-amyloid (A $\beta$ ) peptide. Current treatments for AD include cholinesterase inhibitors and glutamate antagonists. Although useful, these symptomatic treatments do not stop the disease process or prevent neuronal degeneration. There is an on-going need for the development of new treatments for AD. Although the central role of $A \beta$ remains to be proven in clinical trials, data accumulated during the past two decades place $A \beta$ peptides and in particular soluble forms of the peptide as being the main molecule initiating the pathological cascade that eventually leads

\section{() Biomed Central}


to AD [1]. Consequently, significant resources have been allocated to identify and develop treatment strategies that alter the metabolism of $A \beta$. To this end, the discovery of new pharmaceutical entities that have $A \beta$-lowering ability remains a priority.

$\mathrm{A} \beta$ peptides are derived from the sequential proteolysis of the $\beta$-amyloid precursor protein (APP) by $\beta$ - and $\gamma$ secretases. The major $\beta$-secretase is an aspartyl protease termed BACE-1 ( $\beta$-site APP cleaving enzyme) [2-4]. BACE-1 cleaves APP within the extracellular domain of APP, resulting in the secretion of the large ectodomain (APPs $\beta$ ) and generating a membrane-tethered C-terminal fragment CTF $\beta$ or C99 which serves as a substrate for $\gamma$-secretase [5]. The multimeric $\gamma$-secretase complex cleaves at multiple sites within the transmembranous CTF $\beta$ generating $C$-terminally heterogeneous $A \beta$ peptides ranging between 38 to 43 amino-acid residues in length that are secreted [6]. In addition to BACE-1 and $\gamma$-secretase, APP can be cleaved by $\alpha$-secretase within the $\mathrm{A} \beta$ domain between $\mathrm{Lys}^{16}$ and Leu ${ }^{17}$, releasing APPs $\alpha$ and generating CTF $\alpha$ or C83 which is further cleaved by $\gamma$-secretase to generate an N-terminally truncated $A \beta$ termed p3. Genetic ablation of BACE-1 completely abolishes $A \beta$ production, establishing $\mathrm{BACE}-1$ as the major neuronal enzyme responsible for initiating the amyloidogenic processing of APP [7].

Given that BACE- 1 is the initiating enzyme in $A \beta$ generation, it is considered a prime target for lowering $\mathrm{A} \beta$ levels in the treatment and/or prevention of $\mathrm{AD}$. BACE-1 expression is tightly regulated at both the transcriptional and translational level [8]. The BACE-1 gene spans approximately 30 kilobases on human chromosome 11q23.2 and includes 9 exons. The BACE-1 gene promoter lacks the typical CAAT and TATA boxes but contains a variety of transcription factor binding sites, including those for Sp1, GATA-1, AP1, CREB, HSF-1, STAT1, and $\mathrm{NF} \kappa \mathrm{B}$, among others. It is likely that these sites influence transcriptional activity of the BACE-1 promoter. Interestingly, both the expression and activity of BACE-1 appear to be elevated in the cerebrospinal fluid and brains of AD patients $[9,10]$ suggesting that BACE-1 expression is altered in AD and that therapeutic approaches aimed at regulating BACE-1 expression may be successful.

Neurons are believed to be the major source of $A \beta$ and BACE-1. However, evidence is mounting that glia, and astrocytes in particular may produce significant levels of BACE- 1 and $A \beta$, especially during inflammation. Glia out-number neurons by a factor of 10 , so even a slight increase in glial BACE-1 expression might contribute substantially to cerebral $A \beta$ and exacerbate $\mathrm{AD}$ pathology. $\mathrm{NF} \kappa \mathrm{B}$ is increased in $\mathrm{AD}$ and particularly in astrocytes, and it has been suggested that $A \beta$ itself can trigger BACE-1 expression in glial cells via $\mathrm{NF} \kappa \mathrm{B}$ activation [11-15]. BACE-1 expression has been shown to be particularly elevated both in neurons and astrocytes around $\mathrm{A} \beta$ deposits in $\mathrm{AD}$ brains $[16,17,9]$. Thus, pathophysiological conditions leading to the activation of astrocytes may increase BACE-1 expression resulting in increased $A \beta$ production which could exacerbate $A D$ pathogenesis. Small increases in BACE-1 expression have been shown to result in sharply increased $A \beta$ production [18]. Altogether these data suggest that lowering BACE-1 expression levels may have therapeutical potential for AD. We have therefore explored in vitro the effects of various known $\mathrm{NF} \kappa \mathrm{B}$ inhibitors as a way to reduce $B A C E-1$ expression and shown that $N F \kappa B$ inhibitors reduce $A \beta$ production by targeting the $\beta$-cleavage of APP [19]. In the present study, we investigated acute and chronic effects of celastrol, a potent natural triterpene $N F \kappa B$ inhibitor extracted from the roots of the Chinese "Thunder of God vine" (Tripterygenium wilfordii) on $\mathrm{A} \beta$ production and Alzheimer-like pathology in a transgenic mouse model of AD. Root extracts of the "Thunder of God vine" have been used as an antiinflammatory remedy for centuries in China. Celastrol was selected over other known $\mathrm{NF} \kappa \mathrm{B}$ inhibitors for its ability to cross the blood brain barrier and offer neuroprotection in animal models of Parkinson's disease and Huntington's disease [20]. Previous work has revealed that celastrol can prevent neurodegeneration and extend the life span of a transgenic mouse model of amyotrophic lateral sclerosis [21]. Celastrol displays potent anti-inflammatory activities in vivo and has been shown, for example, to be beneficial against allergy-induced asthma [22] as well as rheumatoid arthritis [23] and to inhibit tumor cell invasion through suppression of $\mathrm{NF} \kappa \mathrm{B}$ signaling [24].

\section{Methods}

\section{Cell culture and western-blotting experiments}

$\mathrm{NF} \kappa \mathrm{B}$ activation was quantified using a stable $\mathrm{NF} \kappa \mathrm{B}$ luciferase reporter cell line of HEK293 cells with chromosomal integration of a luciferase reporter construct regulated by 6 copies of the $\mathrm{NF} \kappa \mathrm{B}$ response element (Panomics, CA, USA). Cells were grown in DMEM containing $10 \%$ serum, $1 \%$ penicillin/streptomycin/fungizone and $100 \mu \mathrm{g} / \mathrm{ml}$ of hygromycin B. Confluent cells were treated with $20 \mathrm{pg} / \mathrm{ml}$ of TNF $\alpha$ (Sigma, MO, USA) to induce $\mathrm{NF} \kappa \mathrm{B}$ activation and with a dose range of celastrol for 3 hours. Celastrol was purchased by Gaia Chemical Corporation (CT, USA). Luciferase activity was detected with the Luc-Screen Extended-Glow from Applied Biosystem (CA, USA) and a Synergy HT Biotek chemoluminescent reader (VT, USA). The medium surrounding the cells was collected and used to assess cytotoxicity using a Lactate Dehydrogenase (LDH) assay (Roche Diagnostics, Germany) according to the 
manufacturer's protocol. Similar experiments were also conducted with $100 \mathrm{ng} / \mathrm{ml}$ of phorbol 12-myristate 13 acetate (PMA) purchased from Sigma (MO, USA) instead of TNFa to induce $\mathrm{NF} \kappa \mathrm{B}$ activation (data not shown). HEK293 cells were used to assess the effect of celastrol on the activation of canonical members of the NFkB signaling pathway following PMA stimulation and on BACE-1 expression levels. Briefly, HEK293 cells were treated $100 \mathrm{ng} / \mathrm{ml}$ of PMA or a combination of PMA with celastrol $(5 \mathrm{mM})$ for 15 minutes. Celastrol effects on RAF-1, MEK1/2, p44/42 MAPK and IKBa phosphorylation were monitored by western-blots as detailed below.

$7 \mathrm{~W}$ CHO cells overexpressing wild-type human APP [25] were grown in DMEM (ATCC, VA, USA) containing $10 \%$ fetal bovine serum (Invitrogen, CA, USA), 1\% penicillin/streptomycin/fungizone (Cambrex, ME, USA) and $0.3 \%$ Geneticin (Invitrogen, CA, USA) and used to determine the impact of celastrol on APP processing and $A \beta$ production. Confluent cells were treated for 24 hours with different doses of celastrol.

Cellular proteins were extracted with $150 \mu \mathrm{L}$ of icecold M-PER Reagent (Pierce Biotechnology, Rockford, IL, USA) containing $1 \mathrm{mM}$ phenylmethanesulfonyl fluoride, $1 \times$ of protease cocktail inhibitor (Roche, Inc., USA) and $1 \mathrm{mM}$ sodium orthovanadate. Samples were sonicated, denatured by boiling in Laemmli buffer (BioRad, Hercules, CA, USA) and resolved onto 4-20\% gradient polyacrylamide gels (Bio-Rad, Hercules, CA, USA). After electrotransfering onto polyvinylidene difluoride membranes, western-blots were immunoprobed with an anti-APP C-terminal (751-770) antibody (EMD Biosciences Inc., San Diego, CA, USA), with an anti-actin antibody (Chemicon, Temecula, CA, USA) used as a reference antibody to quantify the amount of proteins electrotransferred, with a BACE-1 antibody (Invitrogen, CA, USA), with a phospho-IKB $\alpha$ (ser32) antibody, with a phospho-NF $\kappa \mathrm{B}$ p65 (ser 536) antibody, with a phospho-Raf-1 (Ser338) antibody, with a phospho-MEK1/2 and a phospho-p44/42 MAPK antibody using dilutions recommended by the manufacturers. All phospho-specific antibodies were purchased from Cell Signaling Technology Inc (MA, USA). Additionally, sAPP $\alpha$ was detected by Western-blot in the culture medium surrounding $7 \mathrm{~W}$ CHO cells using the antibody 6E10 (Signet Laboratories Inc., MA, USA) which recognizes the amino-acids 1-17 of $A \beta$ and sAPP $\beta$ was detected in the culture medium using an anti-human sAPP $\beta$ antibody (Immuno-Biological Laboratories Co. Ltd., Gunma, Japan). APP CTF/actin, sAPP $\beta / \mathrm{sAPP} \alpha$ signals, phosphoIKB $\alpha$ /actin, phospho-NF $\kappa$ B p65/actin, phpspho-RAF-1/ actin, phospho-MEK/actin, phospho-p44/42 MAPK/ actin, BACE-1/actin signal intensity ratios were quantified by chemiluminescence imaging with the
ChemiDocTM XRS (Bio-Rad, Hercules, CA, USA). A $\beta$ 1-40 and $A \beta$ 1-42 were quantified in the culture media of $7 \mathrm{~W}$ CHO cells using commercially available ELISAs following the manufacturer's recommendations (Invitrogen, CA, USA).

Short hairpin RNAs (shRNAs) were used to stably knock-down the cdc37 gene in HEK293 cells overexpressing APPsw cells. Three different cdc37 shRNAs and a scrambled control shRNA (control cells) were used for transfection. Cdc37 shRNAs cloned into the pRs vector were purchased from Origene (Rockville, MD, USA). Approximately one million HEK/APPsw cells detached with TripLE (Invitrogen, IL, USA) were mixed together with $10 \mu \mathrm{g}$ of shRNA vectors in Bio-Rad (Hercules, CA, USA) gene pulser cuvettes and electroporated using a square wave protocol $(110 \mathrm{~V}$, one $25 \mathrm{~ms}$ pulse length using a Bio-Rad gene pulser). Forty-eight hours after, the culture media were replaced by selective media containing $6 \mu \mathrm{g} / \mathrm{ml}$ of puromycin for stable selection of transfected cells. Single colonies resistant to puromycin were isolated. Western-blots were run with cell lysates from these clones to confirm silencing of the cdc37 gene using a 1:1000 dilution of an anti-cdc37 (V367) antibody (Cell Signaling Technology Inc, MA, USA). BACE-1 expression and APP-CTF levels were monitored in cdc37 knock-down HEK293 APPsw cells and HEK293 APPsw cells transfected with a scrambled control shRNA vector as described above.

In order to inhibit HSP90, HEK293 APPsw overexpressing cells were treated for 24 hours with 10 and 20 $\mu \mathrm{M}$ of gedunin (Tocris, MI, USA), a known HSP90 inhibitor which has been shown to inhibit HSP90 with an IC50 ranging from $3 \mu \mathrm{M}$ to $8 \mu \mathrm{M}$ in function of the cell type used [26]. Following 24 hours treatment with gedunin, cellular lysates were prepared and assayed for BACE-1 expression and APP-CTF levels by western blotting as described above.

The effect of celastrol on the disruption of the cdc37HSP90 complex was tested in HEK293 cells overexpressing APPsw. Briefly, HEK293 APPsw cells were treated with PMA $100 \mathrm{ng} / \mathrm{ml}$ and celastrol $5 \mu \mathrm{M}$ for 3 hours. Cellular lysates were prepared as described above and immunoprecipited overnight at $4^{\circ} \mathrm{C}$ with a $1: 100$ dilution of an HSP90 antibody (Cell Signaling Technology Inc, MA, USA). Protein A sepharose (GE Healthcare, NJ, USA) was used to pull down the immunoprecipitated complex which was denatured and analyzed by westernblotting for the presence of cdc37.

\section{Animals and treatments}

All the experimentations involving mice were approved by the Institutional Animal Care and Use Committee of the Roskamp Institute. Transgenic mice overexpressing the human APP695sw mutation and the presenilin-1 
mutation M146L (Tg PS1/APPsw) resulting in over production of human APP and A $\beta$ [27] were used to assess the effect of celastrol on brain $A \beta$ levels. These transgenic mice typically start to develop $A \beta$ deposits by 4 month of age and display a significant amount of $A \beta$ deposits by 6 months [27,28]. An acute treatment regimen was first tested by injecting intraperitoneally 35 week-old Tg PS1/APPsw (post plaque formation) with $1 \mathrm{mg} / \mathrm{Kg}$ body weight of celastrol $(\mathrm{n}=7)$ or with $100 \mu \mathrm{L}$ of the vehicle (50\% DMSO in PBS, $\mathrm{n}=7$ ) daily for 4 days. One hour after the last injection, brains of the animals were collected, snap frozen in liquid nitrogen and stored at $-80^{\circ} \mathrm{C}$.

Custom made biodegradable pellets ensuring a continuous release of celastrol at $2.5 \mathrm{mg} / \mathrm{Kg}$ of body weight/ day and placebo pellets were obtained from Innovative Research of America (FL, USA). Pellets were implanted subcutaneously in 5 month-old Tg PS1/APPsw mice (placebo $n=7$; celastrol $n=7$ ) when $A \beta$ deposits are forming. After one month (32 days) of treatment, one brain hemisphere for each mouse was snap frozen in liquid nitrogen and stored at $-80^{\circ} \mathrm{C}$ whereas the other hemisphere was fixed in $4 \%$ paraformaldehyde for 48 hours at $4^{\circ} \mathrm{C}$ prior to embedding in paraffin using a Tissue-Tek automated embedding system (Sakura, USA).

\section{Brain $A \beta$ quantifications}

Mice brains (not including the cerebellum) were homogenized by sonication in ice cold MPER reagent containing $1 \mathrm{mM}$ PMSF, $100 \mathrm{mM}$ sodium orthovanadate and $1 \times$ cocktail of protease inhibitors (Pierce protein research product, IL, USA). Brain homogenates were centrifuged at $4^{\circ} \mathrm{C}$ for $30 \mathrm{~min}$ at $15000 \mathrm{rpm}$. The supernatant containing soluble A $\beta$ (GS) was collected and treated with $5 \mathrm{M}$ guanidine isothiocyanate for 1 hour at room temperature. The pellet containing insoluble $A \beta$ (GI) was dissolved and denatured in $5 \mathrm{M}$ guanidine isothiocyanate. Protein concentrations were estimated in both fractions by the BCA method (Pierce, IL). For the mice that received an acute treatment with celastrol, $A \beta$ 1-40 and $\mathrm{A} \beta$ 1-42 were quantified by ELISAs according to the manufacturer's recommendations (Invitrogen, CA, USA). For the mice that received the chronic celastrol treatment, $A \beta$ 1-38, $A \beta$ 1-40 and $A \beta$ 1-42 were quantified by electrochemoluminescence in GI and GS fractions using multiplex $A \beta$ assays according to the manufacturer's recommendations (Meso Scale Discovery, MD, USA). A $\beta$ concentrations were calculated in $\mathrm{pg} / \mathrm{mg}$ of protein and expressed as a $\%$ of $A \beta$ obtained in the vehicle/placebo treated animals.

\section{Immunohistochemistry}

Paraffin embedded brains were sagitally cut into $5 \mu \mathrm{m}$ thick sections with a microtome (2030 Biocut, Reichert/
Leica, Germany). Sections were mounted on slides and air-dried. Prior to staining, sections were deparaffinized in xylene $(2 \times 5 \mathrm{~min})$ and hydrated in graded ethanol $(2 \times 5 \mathrm{~min}$ in $100 \%, 5 \mathrm{~min}$ in $85 \%, 5 \mathrm{~min} 70 \%)$ to water. Endogeneous peroxidase activity was quenched with a $20-$ min- $\mathrm{H} 2 \mathrm{O} 2$ treatment $(0.3 \%$ in water) and after being rinsed, sections were incubated with blocking buffer (Protein Block Serum-free, DakoCytomation) for 20 min. The monoclonal antibody $4 \mathrm{G} 8$ was used to stain $A \beta$ deposits at a 1:750-dilution and purchased from Signet Laboratories (MA, USA). CD45 was immunodetected using a 1:50-dilution of a rat monoclonal antibody (clone IBL-3/16) from Serotec (NC, USA) and used as a microglial marker as previously described [29]. The diluted antibodies were applied onto the sections overnight at $4^{\circ} \mathrm{C}$ and were detected using the Vectastain $\mathrm{ABC}$ (avidin-biotin-peroxidase complex) Elite kit (Vector Laboratories, CA). The labeling was revealed by incubating sections in $0.05 \mathrm{M}$ Tris- $\mathrm{HCl}$ buffer ( $\mathrm{pH}$ 7.6) containing 3,3'-diaminobenzidine (Sigma, $\mathrm{MO}$ ) and $\mathrm{H}_{2} \mathrm{O}_{2}$. For each brain, 4 to 5 stained sections were used to perform the quantification of 4G8 burden and 3 sections were used for the quantification of CD45 burden. The stained area within particular regions (hippocampus, cortex) was quantified using Image-Pro Plus software (Media Cybernetics, MD). An average value was calculated for each brain area from individual mice and expressed as a percentage of the total brain area examined.

\section{Statistical analyses}

For statistical analyses, ANOVA, post-hoc comparisons and $t$-tests were performed where appropriate using SPSS for Windows release 12.0.1.

\section{Results}

\section{In vitro effects of celastrol}

Celastrol (3-Hydroxy-24-nor-2-oxo-1(10),3,5,7-friedelatetraen-29-oic acid) is a natural triterpene lactone epoxide compound (Figure 1A) extracted from the root bark of the Chinese medicine "Thunder of God Vine" which has been used for hundreds of years as a natural remedy for inflammatory conditions. Celastrol appears to potently inhibit $\mathrm{NF} \kappa \mathrm{B}$ activation induced by $\mathrm{TNF} \alpha$ as monitored by measuring luciferase activity in a stable $\mathrm{NF} \kappa \mathrm{B}$ reporter HEK293 cell line with a half maximal inhibitory concentration $\left(\mathrm{IC}_{50}\right)$ below $1 \mu \mathrm{M}$ (Figure $1 \mathrm{~B}$ ) and no cytotoxicity was observed for doses of celastrol up to 5 $\mu \mathrm{M}$ (Figure 1C). Similar data were observed with celastrol when phorbol ester (PMA) was used in place of $\mathrm{TNF} \alpha$ to induce NF $\kappa \mathrm{B}$ signaling (data not shown). We investigated the possible effect of celastrol on some members of the canonical $\mathrm{NF} \kappa \mathrm{B}$ pathway following 15 minutes of stimulation with PMA. As expected, we observed that PMA rapidly stimulated the 


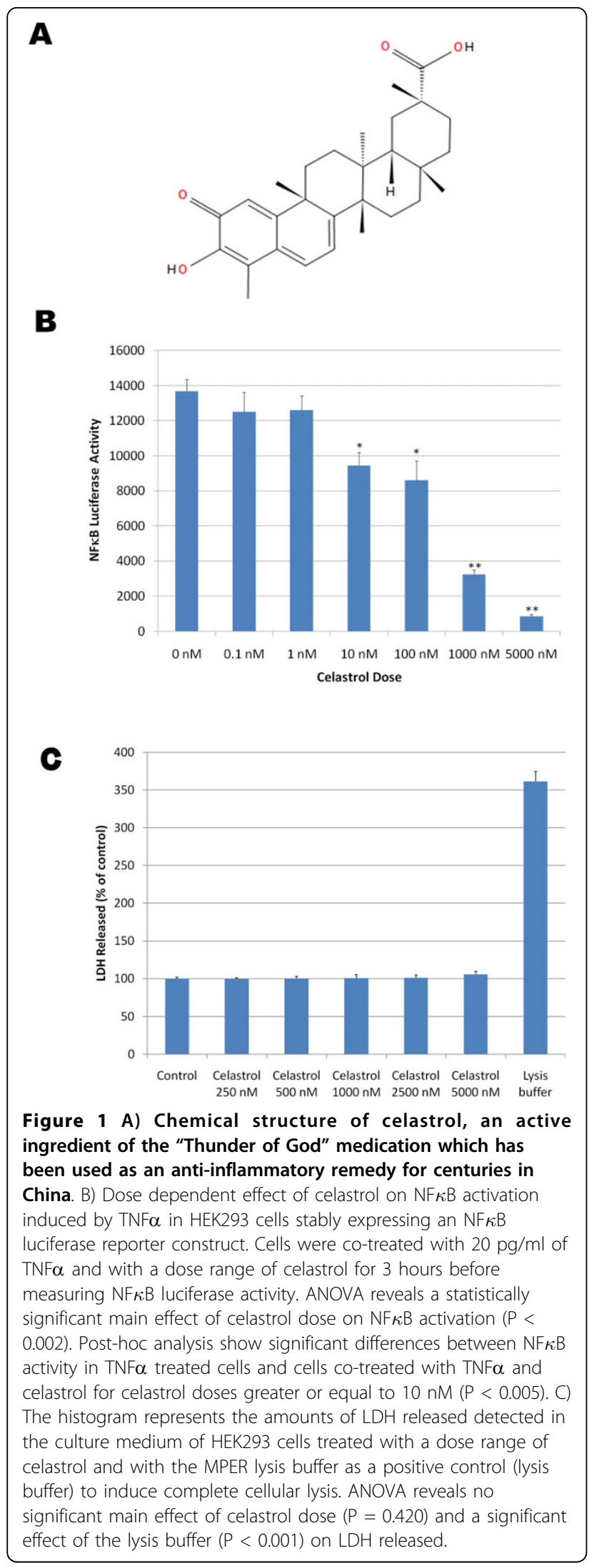

phosphorylation of RAF1, MEK1/2, p44/42 MAPK and IKB $\alpha$ (Figure 2). Interestingly, celastrol did not prevent PMA induced phosphorylation of RAF1, MEK1/2 and $\mathrm{p} 44 / 42$ MAPK but inhibited PMA induced IKB $\alpha$ phosphorylation suggesting that celastrol inhibits the activity of the IKK (IKappa B Kinase) signaling complex. The IKK signaling complex is also comprised of the catalytic components IKK $\alpha, I K K \beta$ and of the regulatory subunit NEMO (NF $\kappa \mathrm{B}$ essential modifying factor) which integrates upstream signals and leads to the phosphorylation of IKB $\alpha$ and $\mathrm{NF} \kappa \mathrm{B}$. Subsequently, phosphorylated IKB $\alpha$ is ubiquitinated and rapidly degraded allowing the localization signal for $\mathrm{NF} \kappa \mathrm{B}$ nuclear translocation to be exposed.

We used $7 \mathrm{~W}$ CHO cells overexpressing wild-type human APP [25] to assess the effect of celastrol on A $\beta$ production and APP processing. Following a 24 hours treatment, celastrol inhibited $A \beta_{1-42}$ and $A \beta_{1-40}$ production with an $\mathrm{IC}_{50}$ of approximately $900 \mathrm{nM}$ (Figure 3A) in $7 \mathrm{~W} \mathrm{CHO}$ cells overexpressing APP. Analysis of metabolites of the APP pathway reveals that celastrol impairs the cleavage of APP at the $\beta$-secretase cleavage site leading to a decreased SAPP $\beta$ and concomitant suppression of the APP-CTF $\beta$ (C99) fragment (Figure 3B). No significant effect of celastrol was observed on APPs $\alpha$ secretion indicating that celastrol does not affect the $\alpha$-secretase cleavage of APP despite a reduction in APP-CTF $\alpha$ (C83) at 5 $\mu \mathrm{M}$, therefore suggesting that celastrol may affect the stability or turn-over of C83 (Figure 3B). We did not find that celastrol directly affects BACE-1 activity in a cell free assay at doses inhibiting $A \beta$ production in whole cells (data not shown). A dose dependent inhibition of IKB $\alpha$ and NF $\kappa \mathrm{B}$ p 65 phosphorylation was observed with celastrol confirming that celastrol inhibited basal $\mathrm{NF} \kappa \mathrm{B}$ activity in $7 \mathrm{~W} \mathrm{CHO}$ cells overexpressing APP at doses affecting APP processing (Figure 3). We investigated the effect of celastrol and $\mathrm{NF} \kappa \mathrm{B}$ stimulation with PMA on BACE-1 expression in HEK293 cells overexpressing APPsw (Figure 4). Celastrol inhibited basal BACE-1 expression and opposed the stimulation of BACE-1 expression induced by PMA. In parallel with the reduction of BACE-1 expression induced by celastrol, a reduction in APP-CTF $\beta$ was observed. Moreover, an increased in APP-CTF $\beta$ and BACE-1 levels was observed when $\mathrm{NF} \kappa \mathrm{B}$ signaling was stimulated by PMA (Figure 4) suggesting that celastrol affects APP processing by regulating BACE-1 expression via an NF $\kappa$ B dependent mechanism. Similarly, using a neuronal like cell line (SHSY), we observed that celastrol can reduce BACE-1 expression and oppose PMA induced BACE-1 expression (data not shown).

Since the formation of a transient complex between cdc37 and HSP90 may be required to allow IKK activation [30] and celastrol may interfere with HSP90 or 

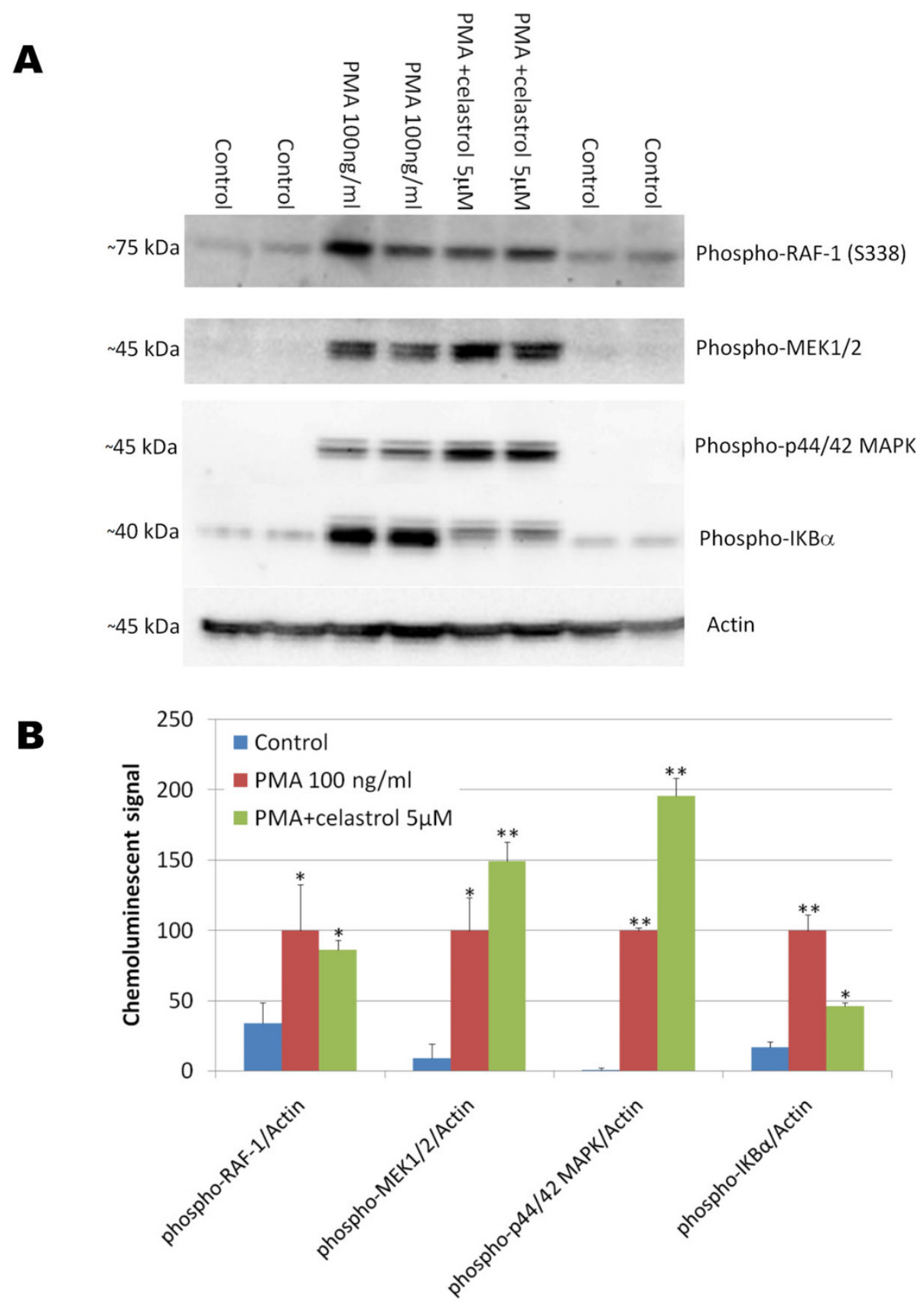

Figure 2 Effect of celastrol on phorbol ester (PMA) induced phosphorylation of key members of the NF $\kappa$ B signaling pathway. HEK293 cells overexpressing APPsw were treated for 15 minutes with PMA in the presence of $0 \mu \mathrm{M}$ and $5 \mu \mathrm{M}$ of celastrol. A) Western blots reveal that celastrol did not inhibit Raf-1 phosphorylation, MEK1/2 phosphorylation or p44/42 MAPK phosphorylation induced by PMA but prevented IKB $\alpha$ phosphorylation induced by PMA suggesting that celastrol is inhibiting IKK activity. B) Histogram representing the quantification of Raf-1 phosphorylation/actin, MEK1/2 phosphorylation/actin, phospho p44/42 MAPK/actin and IKB $\alpha$ phosphorylation/actin chemoluminescent signal. ANOVA shows a significant main effect of PMA on the phosphorylation of these different proteins $(P<0.05)$. Post-hoc comparisons reveal significant increase in phosphorylation after PMA treatment for Raf-1 $(P<0.04)$, MEK1/2 $(P<0.01)$, p44/42 MAPK $(P<0.001)$ and IKB $\alpha(P<0.001)$ compared to the control conditions. Celastrol does not appear to prevent PMA induced Raf-1 phosphorylation $(P=0.619)$ but leads to a significant stimulation of MEK1/2 and p44/42 MAPK compared to PMA treatment alone $(\mathrm{P}<0.02)$ and significantly inhibited IKB $\alpha$ phosphorylation compared to PMA treatment alone $(P<0.001)$. 
A

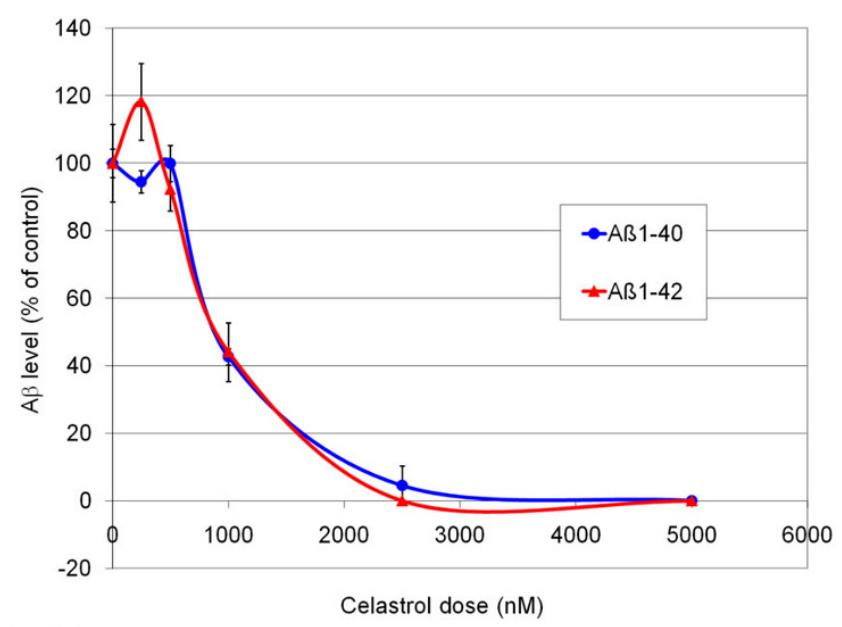

B

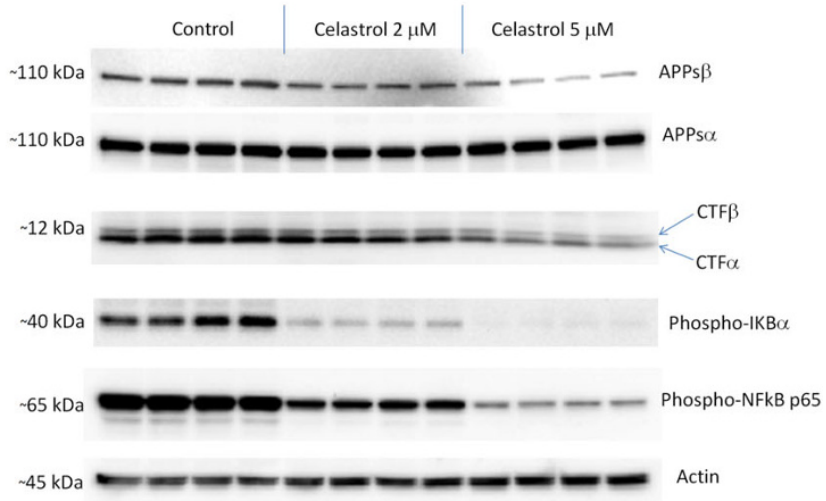

C

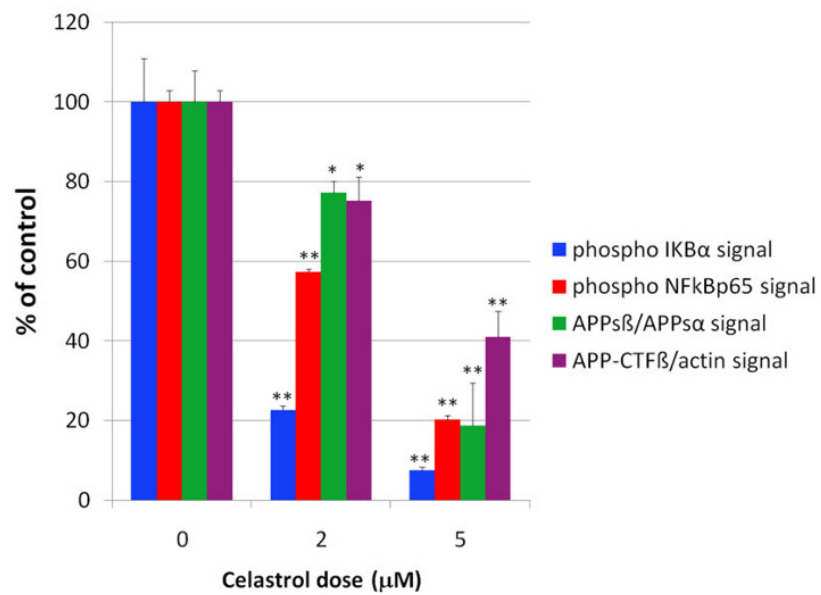

Figure 3 A) Effect of celastrol on $\mathbf{A} \boldsymbol{\beta}$ production in $\mathbf{7} \mathbf{W} \mathbf{C H O}$ cells overexpressing wild-type human APP. Human A $\beta$ was measured by ELISAs in the culture media surrounding the cells following 24 hours of treatment with different doses of celastrol. Dose response curves for both $A \beta_{1-40}$ and $A \beta_{1-42}$ were established revealing an IC 50 of approximately $900 \mathrm{nM}$ for celastrol. ANOVA reveals a significant main effect of celastrol on $A \beta 1-40(P<0.001)$ and $A \beta 1-42$ production $(P<0.015)$. Post-hoc comparisons show statistically significant effects of celastrol at $1000 \mathrm{nM}, 25000$ $\mathrm{nM}$ and $5000 \mathrm{nM}$ for both $\mathrm{A} \beta 1-40$ and $\mathrm{A} \beta$ 1-42 (P<0.001). B) Effect of celastrol on APP processing and NF $\kappa B$ in $C H O$ cells overexpressing wildtype human APP. Celastrol dose dependently inhibited APPs $\beta$ secretion, APP-CTF $\beta$ level as well as NF $\kappa$ B p65 and IKB $\alpha$ phosphorylation. C) Histogram representing the quantification of APPs $\beta / A P P s \alpha$, APP-CTF $\beta$ /actin as well as phospho-NF $\kappa B$ p65/actin and phospho-IKB $\alpha / a c t i n$ chemoluminescent signals. ANOVA reveals a significant main effect of celastrol on APPs $\beta$ secretion, APP-CTF $\beta$ level, phospho-NF $\kappa B$ p 65 and phospho-IKB $\alpha$ levels $(P<0.001)$. Post-hoc comparisons show a statistical significance for celastrol at 2 and $5 \mu \mathrm{M}$ for all the parameters studied $(P<0.05)$ showing that celastrol dose dependently inhibits the $\beta$-cleavage of APP while suppressing NF $\kappa B$ activity. $\left({ }^{*} P<0.05\right.$; $\left.{ }^{* *} P<0.001\right)$. 
A

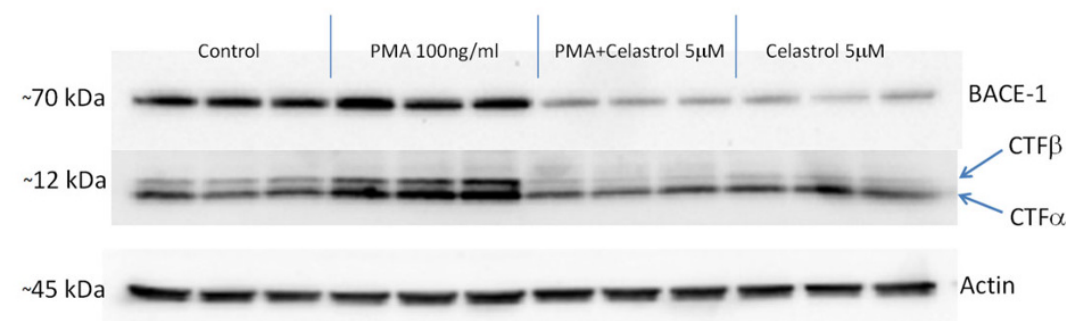

$\mathbf{B}$

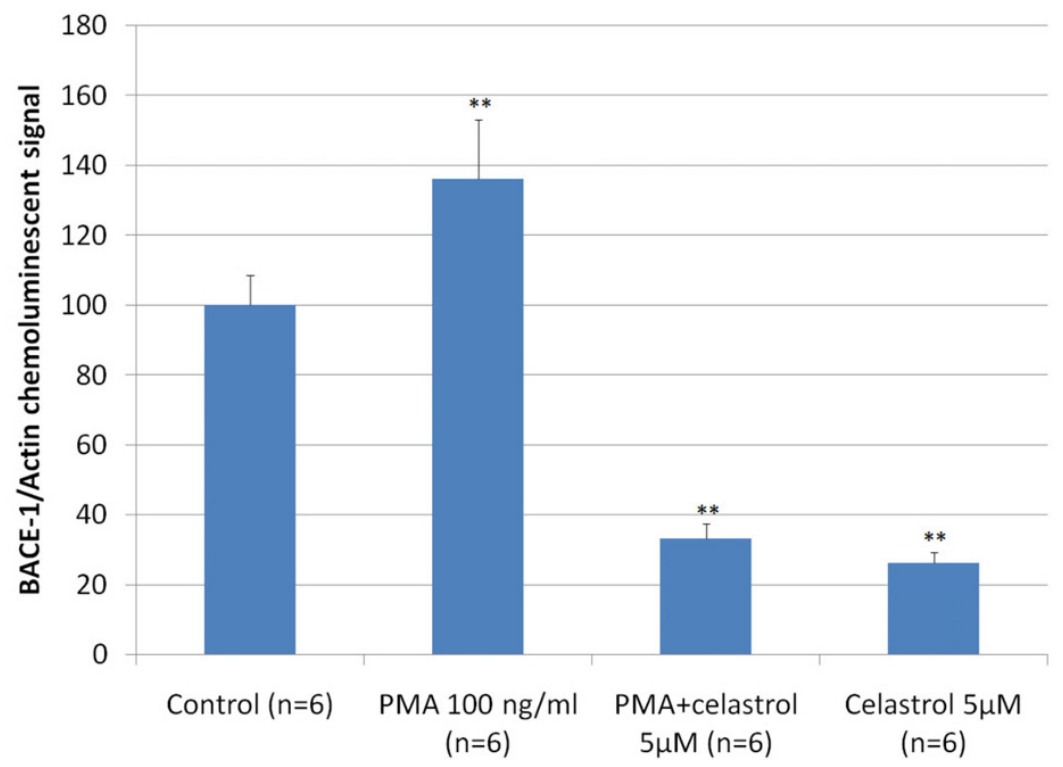

Figure 4 A) Representative western-blot depicting the effect of celastrol on BACE-1 expression in HEK293 cells overexpressing APPsw Celastrol inhibited basal BACE-1 expression as well as the stimulation of BACE-1 expression induced by a 24 hours treatment with PMA. APPCTF $\beta$ level is reduced when BACE-1 expression is inhibited by celastrol and APP-CTF $\beta$ level is increased when BACE-1 expression is stimulated by PMA. B) Histogram representing the quantification of BACE-1 expression in response to celastrol and PMA treatments. ANOVA reveals a significant main effect of PMA $(P<0.002)$ and of celastrol $(P<0.001)$ on BACE-1 expression. Post-hoc comparisons shows that PMA significantly stimulates BACE-1 level $(P<0.002)$ whereas celastrol significantly reduces BACE-1 expression $(P<0.001)$ compared to control condition and opposes BACE-1 stimulation induced by PMA $(P<0.001)$. $\left.{ }^{* *} P<0.002\right)$.

cdc37 [31,32], we explored the effect of celastrol on the formation of this complex in HEK293 cells overexpressing APPsw. Data show that at a dose $(5 \mu \mathrm{M})$ that fully inhibits $\mathrm{NF} \kappa \mathrm{B}$ activation and $\mathrm{A} \beta$ production, only a slight reduction of cdc37 was observed in the immunoprecipitated HSP90 complex (Figure 5A and 5B). No effect of the NF $\kappa \mathrm{B}$ stimulator PMA was observed on the stability of this complex. We next inhibited HSP90 in HEK293 APPsw cells using gedunin, a known HSP90 inhibitor [26] which induces the degradation of HSP90-dependent client proteins similarly to other HSP90 inhibitors. Gedunin did not appear to affect BACE-1 expression or APP processing (Figure 5C and 5D). Moreover, we stably knock-down cdc37 expression in HEK293 APPsw cells using a shRNA approach and observed that cdc37 inhibition did not impact BACE-1 expression (Figure 5E and $5 \mathrm{~F}$ ) and APP processing (data not shown).
Acute effect of celastrol on $A \beta$ production in a transgenic mouse model of $A D$

We next investigated the effect of celastrol on brain $A \beta$ levels using an acute dosage paradigm in 6-month old Tg PS1/APPsw mice. Tg PS1/APPsw mice were injected intraperitoneally, daily for 4 days, with $1 \mathrm{mg} / \mathrm{Kg}$ of body weight of celastrol or $100 \mu \mathrm{L}$ of the vehicle only. One hour after the last injection, mice were humanely euthanatized and their brains collected. We assessed the $\beta$-amyloid lowering properties of celastrol by measuring the pools of soluble and insoluble $A \beta$ species in celastrol and placebo treated mice. Following 4 days of treatment with $1 \mathrm{mg} / \mathrm{Kg} /$ day of celastrol, we observed a reduction in brain soluble $A \beta$ 1-40 and $A \beta$ 1-42 by approximately $40 \%$ whereas insoluble $A \beta$ was reduced by approximately $50 \%$ compared to placebo treated animals (Figure 6). 


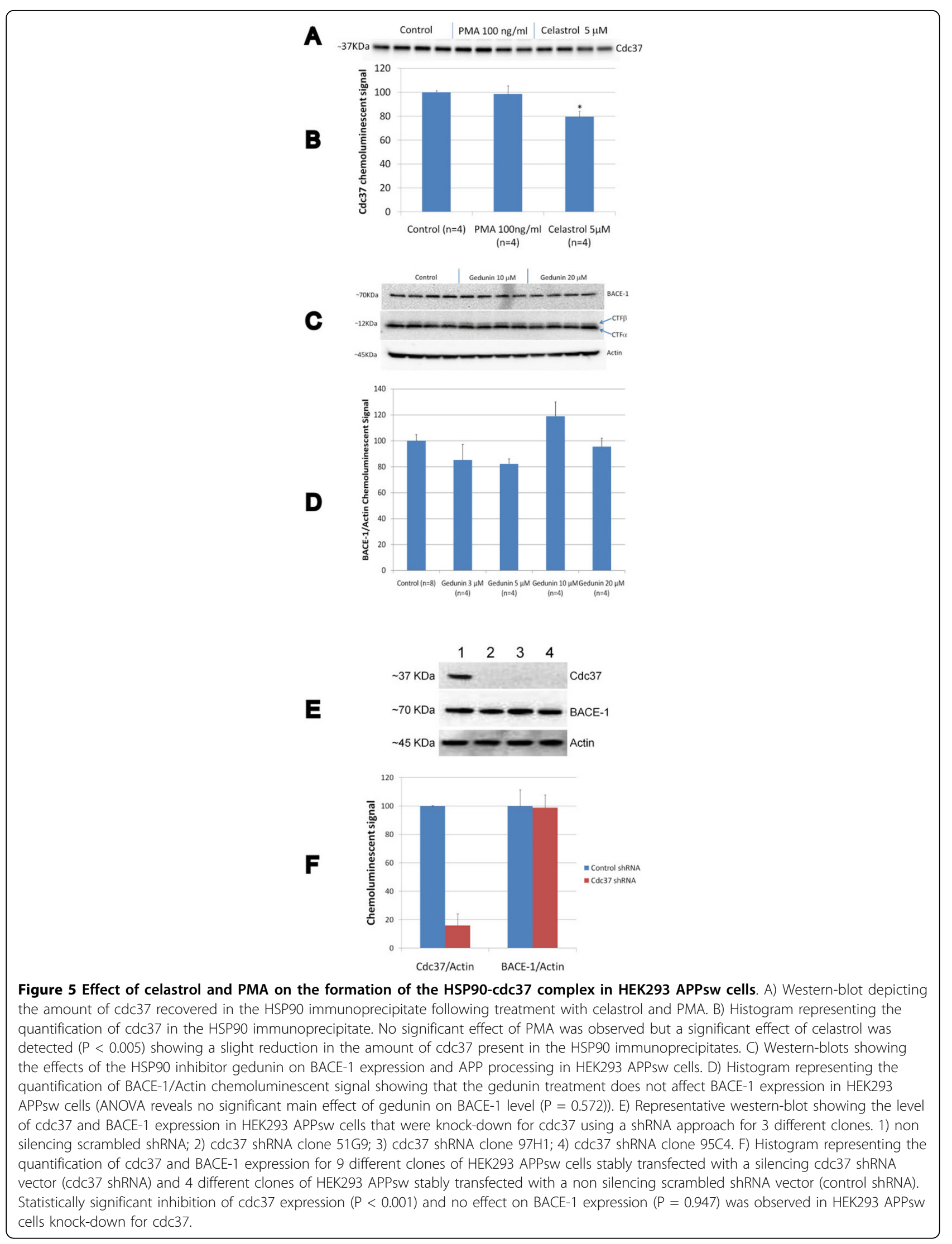




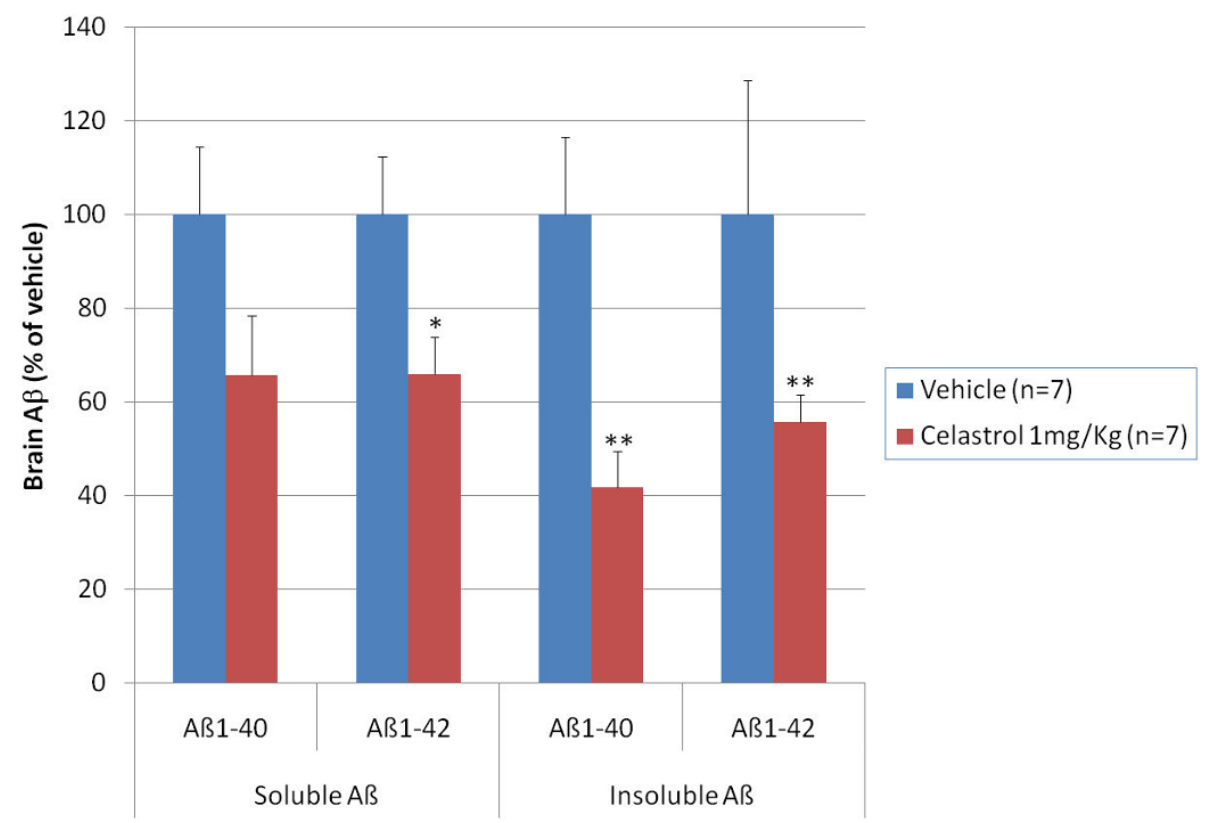

Figure 6 Acute effects of celastrol on brain A $\boldsymbol{\beta}$ levels in 35 week-old Tg PS1/APPSw. Mice were treated for 4 days with an intraperitoneal injection of celastrol $(1 \mathrm{mg} / \mathrm{Kg}$ of body weight) or the vehicle only (placebo). Multivariate analysis reveals a significant main effect of celastrol on brain soluble and insoluble $A \beta$ levels $(P<0.05)$. Statistically significant differences were observed for soluble $A \beta \quad 1-42$ values $(P<0.03)$ between vehicle and celastrol treated mice and for insoluble $A \beta 1-40(P<0.001)$ and $A \beta 1-42$ values $(P<0.001)$ between vehicle and celastrol treated mice. ( ${ }^{*} P<0.05$; ${ }^{* *} P<0.001$ ).

\section{Chronic effect of celastrol on Alzheimer-like pathology in a transgenic mouse model of $A D$}

To evaluate whether celastrol could affect Alzheimerlike pathology in Tg PS1/APPsw, we investigated the effects of a longer treatment with celastrol. We used a matrix-driven delivery pellet system implanted subcutaneously that was designed to ensure a continuous delivery of celastrol and avoid subjecting the animals to repeated injections and excessive handling. Tg PS1/ APPsw mice were treated for one month with this pellet delivery system at a dosage of $2.5 \mathrm{mg}$ of celastrol/ $\mathrm{Kg}$ of body weight/Day. Analysis of brain A $\beta$ levels by ELISAs revealed that celastrol reduced brain soluble $A \beta$ 1-38, $A \beta \quad 1-40$ and $A \beta \quad 1-42$ by approximately $50 \%$ and the levels of insoluble $A \beta$ 1-38, $A \beta \quad 1-40$ and $A \beta$ 1-42 by approximately $60 \%$ (Figure 7 ). To determine whether celastrol treatment affected $\beta$-amyloid plaque pathology, brain sections from Tg PS1/APPSw mice implanted with a placebo pellet and Tg PS1/APPSw mice implanted with a celastrol pellet were immunostained with the antibody $4 \mathrm{G} 8$ recognizing $A \beta$. A significant reduction in plaque burden (approximately $50 \%$ ) in both the hippocampus and the cortex of celastrol treated animals compared to animals receiving the placebo was observed (Figure 8). We also estimated the impact of celastrol on microglial activation by measuring the percentage of CD45 immunostained area [29] on brain sections in placebo and celastrol treated animals. An approximate $50 \%$ reduction in microgliosis was observed in the cortex of celastrol treated animals compared to placebo treated animals (Figure 9).

\section{Discussion}

$\mathrm{NF} \kappa \mathrm{B}$ has been shown to regulate BACE-1 expression level $[11,17,13-15]$, the rate limiting enzyme responsible for the production of $A \beta$. For this reason, we investigated whether $\mathrm{NF} \kappa \mathrm{B}$ inhibition could lead to an inhibition of $A \beta$ accumulation in a transgenic mouse model of AD. In this study, we selected the natural product celastrol over other known $\mathrm{NF} \kappa \mathrm{B}$ inhibitors because it is a potent $\mathrm{NF} \kappa \mathrm{B}$ inhibitor that has been shown to exert anti-inflammatory effects in vivo [33,34] and neuroprotective effects in animal models of Parkinson's disease and Hungtington's disease [20]. We first characterized the in vitro activity of celastrol towards $\mathrm{A} \beta$ production using a $\mathrm{CHO}$ cell line overexpressing $\mathrm{A} \beta$. Celastrol dose dependently inhibited $A \beta_{1-40}$ and $A \beta_{1-42}$ with an IC50 comparable to its IC50 for inhibiting $\mathrm{NF} \kappa \mathrm{B}$ activation in response to TNF $\alpha$ (around $900 \mathrm{nM}$ ). Celastrol dose dependently reduced the production of APP-CTF $\beta$ and APPs $\beta$ confirming that celastrol impacted the $\beta$-cleavage of APP. Moreover, celastrol appeared to reduce BACE-1 expression and to oppose BACE-1 upregulation induced by $\mathrm{NF} \kappa \mathrm{B}$ stimulation. 


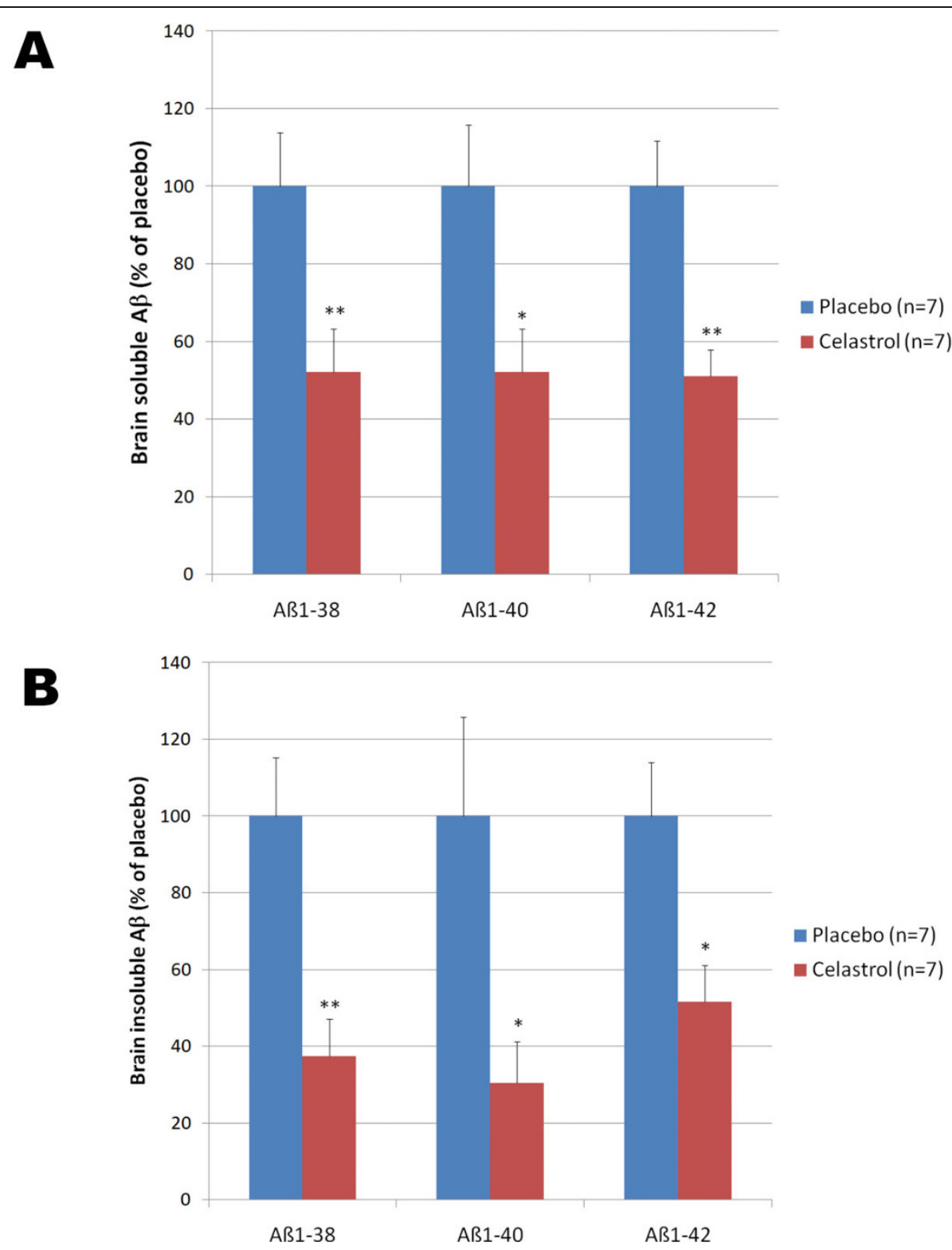

Figure 7 Chronic effects of celastrol on brain $\mathbf{A} \boldsymbol{\beta}$ levels. Five month-old Tg PS1/APPSw mice were implanted subcutaneously with biodegradable placebo pellets and celastrol pellets ensuring a constant release of celastrol at a rate of $2.5 \mathrm{mg} / \mathrm{Kg}$ of body weight/day. After 32 days of treatment, brain $A \beta$ levels were analyzed by electrochemoluminescence. A) Histogram representing the level of soluble $A \beta$ 1-38, $A \beta$ 1-40 and $A \beta$ 1-42 quantified in the brain of placebo and celastrol treated Tg PS1/APPsw mice. B) Histogram representing the level of insoluble A $\beta$ 1-38, $A \beta \quad$ 1-40 and A 1-42 quantified in the brain of placebo and celastrol treated Tg PS1/APPsw mice. Multivariate analysis reveals a statistical significant differences between celastrol and placebo treated mice for the levels of brain soluble $A \beta 1-38(P<0.005), A \beta 1-40(P<0.03)$, A 3 1-42 $(P<0.007)$ and brain insoluble $A \beta 1-38(P<0.004), A \beta 1-40(P<0.03), A \beta 1-42(P<0.02) .\left({ }^{*} P<0.05\right)$; $\left.{ }^{* *} P<0.01\right)$.

We then investigated the impact of celastrol on $A \beta$ production in vivo using a transgenic mouse model of AD. Following an acute treatment with celastrol in Tg PS1/APPsw, we observed a reduction in brain soluble and insoluble $A \beta$ species. We used a biodegradable pellet delivery system implanted subcutaneously to assess the $A \beta$ lowering effects of a chronic treatment with celastrol. After 1 month of treatment, pathological evaluation of the brains of celastrol treated Tg PS1/ APPsw mice showed a $50 \%$ reduction in $A \beta$ plaque burden in the hippocampus and cortex compared to placebo treated animals. Additionally, evaluation of activated microglia following CD45 immunostaining revealed that microgliosis was significantly reduced in celastrol treated animals compared to placebo treated mice paralleling the reduction of $A \beta$ burden observed. 

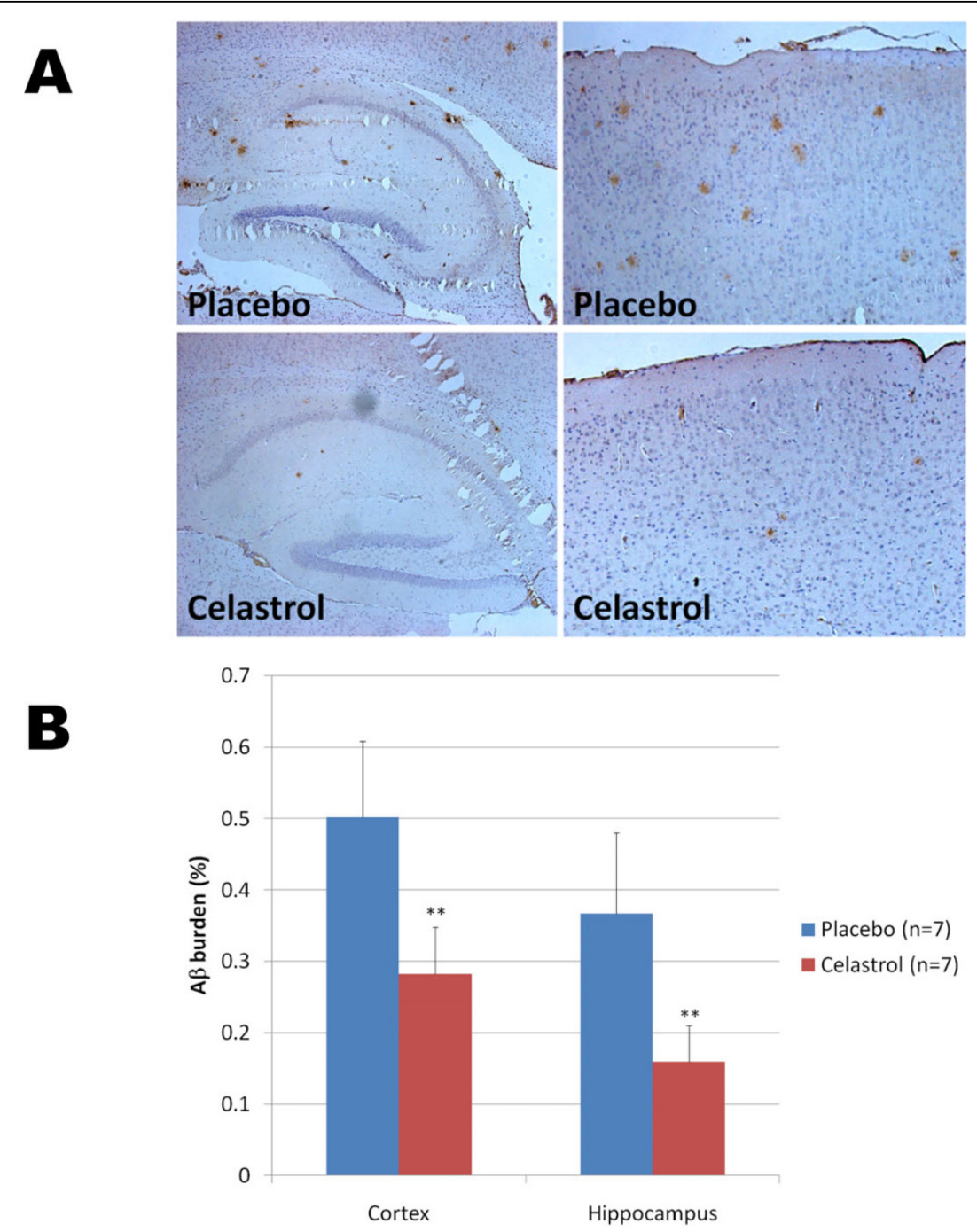

Figure 8 Chronic effects of celastrol on A $\boldsymbol{\beta}$ plaque burden in Tg PS1/APPsw mice. A) Representative photomicrographs (200X magnification) showing the extent of A $\beta$ plaque burden detected by $4 \mathrm{G} 8$ immunostaining in the cortex (right panel) and hippocampus (left panel) of Tg PS1/APPsw mice (6 month-old) treated with biodegradable pellets of placebo or celastrol for a period of 32 days. B) Histogram representing the quantification of A $\beta$ burden by image analysis in the cortex and hippocampus of Tg PS1/APPsw mice treated with placebo and celastrol pellets. Multivariate analysis reveals a statistically significant effect of celastrol treatment on A $\beta$ plaque burden for the cortex $(P<0.002)$ and hippocampus $(P<0.004)$. ( $\left.{ }^{* *} P<0.005\right)$.

We further characterized the $\beta$-amyloid lowering properties of celastrol by measuring the pools of soluble and insoluble $A \beta$ species in celastrol and placebo treated mice. Data showed that this chronic treatment with celastrol in Tg PS1/APPsw mice reduced brain levels of soluble $A \beta$ 1-38, $A \beta \quad 1-40$ and $A \beta \quad 1-42$ by approximately $50 \%$ and the levels of insoluble $A \beta \quad 1-38, A \beta \quad 1-40$ and A $\beta$ 1-42 by approximately $60 \%$.

The exact molecular mechanism of action of celastrol remains unclear. Celastrol has been suggested to be an ERK inhibitor and to inhibit of p44/42 MAPK phosphorylation [35], however our data show that celastrol inhibits $\mathrm{NF} \kappa \mathrm{B}$ activation without preventing the phosphorylation of MEK1/2 and its downstream target p44/42 MAPK when NF $\kappa \mathrm{B}$ is stimulated with PMA, suggesting that celastrol is acting downstream of MAPK. Indeed, celastrol appears to oppose both IKB $\alpha$ and $\mathrm{NF} \kappa \mathrm{B}$ p 65 phosphorylation which suggest that celastrol is inhibiting the IKK complex in agreement with previous studies showing that celastrol inhibits IKK activity [36]. It has been recently suggested that celastrol interacts with HSP90 and disrupts the formation of the cdc37-HSP90 complex [31]. However, NMR analyses of celastrol binding to cdc37 and HSP90 have suggested that celastrol directly interacts with ccd37 and not HSP90 [32]. Interestingly, the formation of a transient 

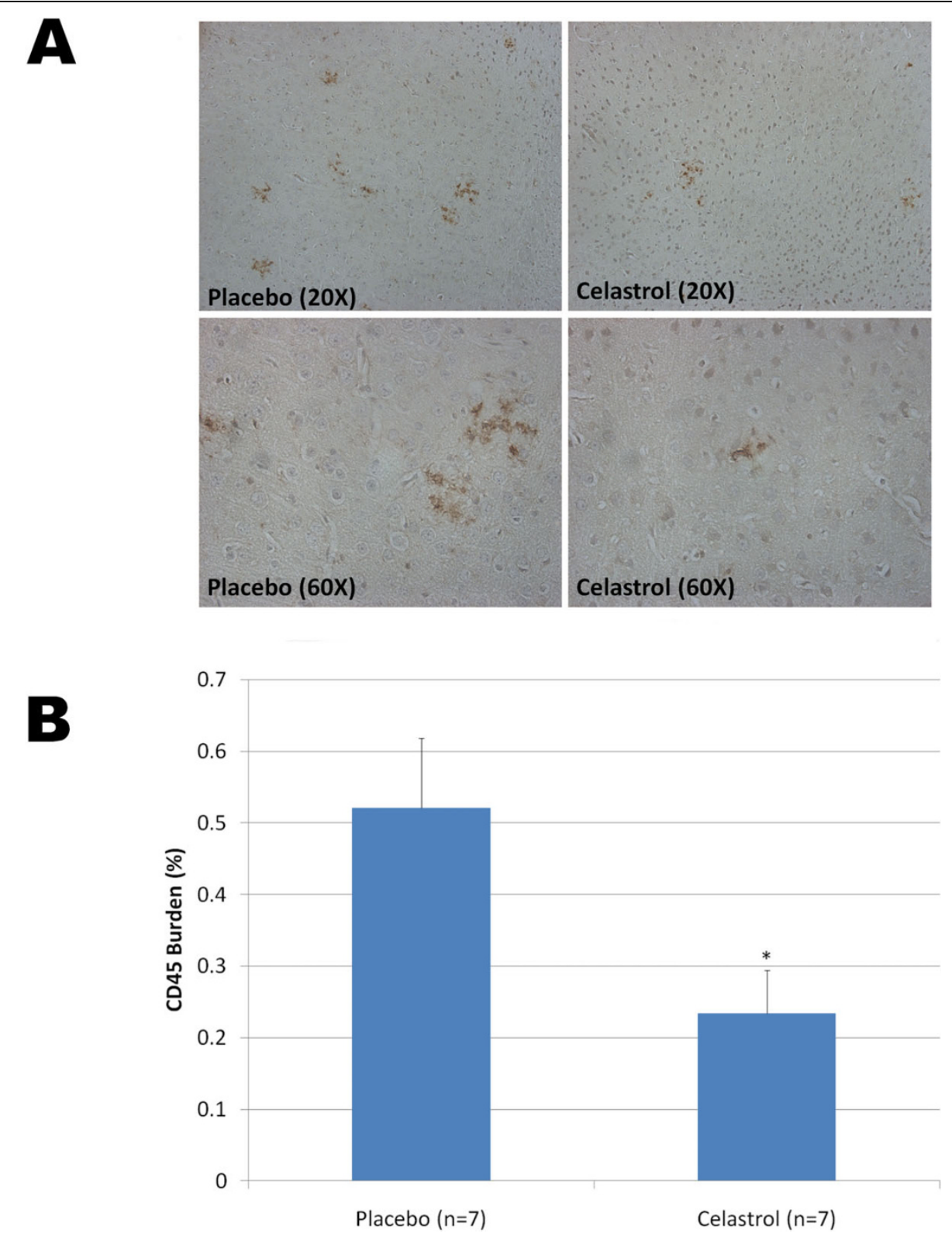

Figure 9 Chronic effects of celastrol on microgliosis in Tg PS1/APPsw mice. A) Representative photomicrographs (taken with a 20x and $60 \times$ objective providing a respective magnification of $200 \times$ and $600 \times$ respectively) depicting the presence of CD45 reactive microglia around A $\beta$ deposits in Tg PS1/APPsw treated with a placebo and celastrol. B) Histogram representing the burden of activated microglia (CD45 positive) in the cortex of Tg PS1/APPsw mice treated with placebo and celastrol pellets. Statistically significant difference in microgliosis burden (P < 0.03$)$ was observed between placebo and celastrol treated mice. $\left({ }^{*} P<0.05\right)$.

complex between cdc37 and HSP90 may be required to allow IKK activation [30] suggesting that celastrol may inhibit $\mathrm{NF} \kappa \mathrm{B}$ activation by preventing the formation of this complex. However, the disruption of the cdc37HSP90 complex by celastrol requires $10 \mu \mathrm{M}$ of celastrol [31] and at $5 \mu \mathrm{M}$ (dose that fully inhibits $\mathrm{A} \beta$ production and $\mathrm{NF} \kappa \mathrm{B}$ activity in vitro), we only observed a modest reduction $(20 \%)$ in the amount of cdc37 co-immunoprecipited with HSP90 suggesting that the effect of celastrol on $\mathrm{A} \beta$ production is unlikely to be mediated via a disruption of this complex. This is further substantiated by our observation that pharmacological inhibition of HSP90 does not significantly affect APP processing and BACE-1 expression, ruling out the possibility that the $A \beta$ lowering properties of celastrol are mediated via HSP90 dependent events. Moreover, inhibition of cdc37 expression does not appear to affect APP processing and BACE-1 expression excluding cdc37 as a molecular 
target responsible for the $A \beta$ lowering properties of celastrol. Celastrol has also been shown to inhibit lipidoperoxydation in vitro with an IC50 of $7 \mu \mathrm{M}$ [37], which is 7-fold higher than it's $\mathrm{IC}_{50}$ for inhibiting $\mathrm{A} \beta$ production; it is therefore unlikely that the antioxidant properties of celastrol play a major role in the $A \beta$ lowering activity of this compound. Overall, our in vitro data suggest that celastrol inhibits $A \beta$ production by regulating BACE-1 expression level most likely via an $\mathrm{NF} \kappa \mathrm{B}$ dependent mechanism.

At doses similar to the doses of celastrol that we tested in vivo, celastrol has been shown to significantly inhibit NF $\kappa \mathrm{B}$ activity in the brain, to reduce TNF $\alpha$ production and the expression of the CD40 ligand in astrocytes [20]. It remains possible that the in vivo $\mathrm{A} \beta$ lowering properties of celastrol may be the result of multiple mechanisms in addition to those affecting APP processing and BACE-1 expression as observed in vitro. For instance, celastrol may also lower brain $A \beta$ levels by opposing inflammation, cytokines production and $\mathrm{CD} 40$ ligand expression, all of which are known to modulate the accumulation of $A \beta$ in the brain [38-40]. So far, we have tested the effects of celastrol on brain $A \beta$ accumulation when $A \beta$ deposits are initially forming in a transgenic mouse model of $\mathrm{AD}$, which could be regarded as an early intervention. It remains to be determined whether celastrol can display therapeutic efficacy when $\mathrm{A} \beta$ deposits are already highly abundant. Interestingly, celastrol has been shown to display neuroprotective effects in different animal models $[20,21]$ and to improve memory, learning and psychomotor activity in rats [34]. Chronic effects of celastrol on memory impairment and tau pathology remain to be investigated in transgenic mouse models of AD to determine whether this compound may offer therapeutic benefits suitable for the treatment of $\mathrm{AD}$.

\section{Conclusions}

Our data suggest that celastrol is a potent $A \beta$ lowering compound that may act in part by decreasing BACE- 1 expression levels and $\mathrm{A} \beta$ production via an $\mathrm{NF} \kappa \mathrm{B}$ dependant mechanism. More experimentation is required to determine the exact mechanism of action responsible for the $A \beta$ lowering properties of celastrol. It remains to be determined whether this compound can also improve cognition and tau pathology in transgenic mouse models of $\mathrm{AD}$ and whether this molecule displays the pharmacokinetic characteristics and toxicity profile required for a drug candidate.

\section{Acknowledgements}

This work was supported by an Alzheimer's Association grant IIRG-08-91076. The authors are grateful to Mr. and Mrs. Roskamp for their generous support which helped to make this work possible. We thank Dr. Michael Wolfe
(Harvard Medical School, Boston, Massachusetts, USA) for providing HEK293 APPsW and 7 W CHO APP overexpressing cells.

\section{Authors' contributions}

DP conceived of the study, developed the methodology for studying APP processing and $\mathrm{NF} \kappa \mathrm{B}$ activity, carried out the in vivo treatments with celastrol, participated in animal care, participated in data analysis and drafted the manuscript. NG and VL carried out the immunostaining studies. NP, DB, AM, CB participated in animal care, samples preparation and carried out some of the western blotting and ELISA studies. GA generated the cdc37 knock-down HEK293 APPsw cells and helped with cell culture experiments. MM helped write the manuscript and gave a critical analysis of the manuscript. All authors read and approved the final manuscript.

\section{Competing interests}

The authors declare that they have no competing interests.

Received: 17 December 2009

Accepted: 8 March 2010 Published: 8 March 2010

\section{References}

1. Selkoe DJ: Soluble oligomers of the amyloid beta-protein impair synaptic plasticity and behavior. Behav Brain Res 2008, 192(1):106-13.

2. Vassar R, Bennett BD, Babu-Khan S, Kahn S, Mendiaz EA, Denis P, Teplow DB, Ross S, Amarante P, Loeloff R, Luo Y, Fisher S, Fuller J, Edenson S, Lile J, Jarosinski MA, Biere AL, Curran E, Burgess T, Louis JC, Collins F, Treanor J, Rogers G, Citron M: Beta-secretase cleavage of Alzheimer's amyloid precursor protein by the transmembrane aspartic protease BACE. Science 1999, 286(5440):735-41.

3. Sinha S, Anderson JP, Barbour R, Basi GS, Caccavello R, Davis D, Doan M, Dovey HF, Frigon N, Hong J, Jacobson-Croak K, Jewett N, Keim P, Knops J, Lieberburg I, Power M, Tan H, Tatsuno G, Tung J, Schenk D, Seubert P, Suomensaari SM, Wang S, Walker D, Zhao J, McConlogue L, John V: Purification and cloning of amyloid precursor protein beta-secretase from human brain. Nature 1999, 402(6761):537-40.

4. Yan R, Bienkowski MJ, Shuck ME, Miao H, Tory MC, Pauley AM, Brashier JR, Stratman NC, Mathews WR, Buhl AE, Carter DB, Tomasselli AG, Parodi LA, Heinrikson RL, Gurney ME: Membrane-anchored aspartyl protease with Alzheimer's disease beta-secretase activity. Nature 1999, 402(6761):533-7.

5. Cole SL, Vassar R: The role of amyloid precursor protein processing by BACE1, the beta-secretase, in Alzheimer disease pathophysiology. J Biol Chem 2008, 283(44):29621-5.

6. Iwatsubo T: Pathogenesis of Alzheimer's disease: implications from amyloid research front. Rinsho Shinkeigaku 2004, 44(11):768-70.

7. Cai H, Wang Y, McCarthy D, Wen H, Borchelt DR, Price DL, Wong PC: BACE1 is the major beta-secretase for generation of Abeta peptides by neurons. Nat Neurosci 2001, 4(3):233-4.

8. Rossner S, Sastre M, Bourne K, Lichtenthaler SF: Transcriptional and translational regulation of BACE1 expression- Implications for Alzheimer's disease. Progress in Neurobiology 2006, 79:95-111.

9. Zhao J, Fu Y, Yasvoina M, Shao P, Hitt B, O'Connor T, Logan S, Maus E, Citron M, Berry R, Binder L, Vassar R: Beta-site amyloid precursor protein cleaving enzyme 1 levels become elevated in neurons around amyloid plaques: implications for Alzheimer's disease pathogenesis. I Neurosci 2007, 27(14):3639-49.

10. Zetterberg $H$, Andreasson $U$, Hansson $O, W u$ G, Sankaranarayanan $S$, Andersson ME, Buchhave P, Londos E, Umek RM, Minthon L, Simon AJ, Blennow K: Elevated cerebrospinal fluid BACE1 activity in incipient Alzheimer disease. Arch Neurol 2008, 65(8):1102-7.

11. Bourne KZ, Ferrari DC, Lange-Dohna C, Rossner S, Wood TG, Perez-Polo JR: Differential regulation of BACE1 promoter activity by $\mathrm{NF} \kappa \mathrm{B}$ in neurons and glia upon exposure to $A \beta$ peptides. J Neurosci Res 2007, 85:1194-1204.

12. Blasko I, Veerhuis R, Stampfer-Kountchev M, Saurwein-Teissl M, Eikelenboom P, Grubeck-Loebenstein B: Costimulatory effect of interferon$\gamma$ and interleukin 1- $\alpha$ or tumor necrosis factor- $\alpha$ on the synthesis of $A \beta 1-$ 40 and A 1-42 by human astrocytes. Neurol Dis 2000, 7:682-689.

13. Hong HS, Hwang EM, Sim HJ, Cho HJ, Boo JH, Oh SS, Kim SU, Mook-Jung I: Interferon gamma stimulates beta-secretase expression and sAPPbeta production in astrocytes. Biochem Biophys Res Commun 2003, 307:922-927. 
14. Rossner S, Apelt J, Schliebs R, Perez-Polo JR, Bigl V: Neuronal and glial $\beta$ secretase (BACE) protein expression in Tg2576 mice with amyloid plaque pathology. J Neurosci Res 2001, 64:437-446.

15. Hartlage-Rübsamen M, Zeitschel U, Apelt J, Gärtner U, Franke H, Stahl T, Günther A, Schliebs R, Penkowa M, Bigl V, Rossner S: Astrocytic expression of the Alzheimer's disease beta-secretase (BACE1) is stimulusdependent. Glia 2003, 41:169-179.

16. Leuba G, Wernli G, Vernay A, Kraftsik R, Mohajeri MH, Saini KD: Neuronal and nonneuronal quantitative BACE immunocytochemical expression in the entorhinohippocampal and frontal regions in Alzheimer's disease. Dem Geriat Cogn Disord 2005, 19:171-83.

17. Rossner S, Lange-Dohna C, Zeitschel U, Perez-Polo JR: Alzheimer's disease beta-secretase BACE1 is not a neuron-specific enzyme. J Neurochem 2005, 92:226-234.

18. Li Y, Zhou W, Tong Y, He G, Song W: Control of APP processing and Abeta generation level by BACE1 enzymatic activity and transcription. FASEB J 2006, 20:285-92.

19. Paris D, Patel N, Quadros A, Linan M, Bakshi P, Ait-Ghezala G, Mullan M: Inhibition of Abeta production by NF-kappaB inhibitors. Neurosci Lett 2007, 415(1):11-16.

20. Cleren C, Calingasan NY, Chen J, Beal MF: Celastrol protects against MPTP and 3-nitropropionic acid neurotoxicity. J Neurochem 2005, 94(4):995-1004.

21. Kiaei M, Kipiani K, Petri S, Chen J, Calingasan NY, Beal MF: Celastrol blocks neuronal death and extends life in transgenic mouse model of amyotrophic lateral sclerosis. Neurodegenrative Dis 2005, 2:246-254.

22. Kim DY, Park JW, Jeoung D, Ro JY: Celastrol suppresses allergen-induced airway inflammation in a mouse allergic asthma model. Eur $J$ of Pharmacol 2009, 612:98-105.

23. Li H, Zhang YY, Tan HW, Jia YF, Li D: Therapeutic effect of tripterine on adjuvant arthritis in rats. J Ethnopharmacol 2008, 118(3):479-84.

24. Sheti G, Ahn KS, Pandey MK, Aggarwal BB: Celastrol, a novel triterpene, potentiates TNF-induced apoptosis and suppresses invasion of tumor cells by inhibiting NF-kappaB-regulated gene products and TAK1mediated NF-kappaB activation. Blood 2007, 109(7):2727-35.

25. Koo EH, Squazzo SL: Evidence that production and release of amyloid beta-protein involves the endocytic pathway. J Biol Chem 1994, 269(26): 17386-9.

26. Brandt GE, Schmidt MD, Prisinzano TE, Blagg BS: Gedunin, a novel hsp90 inhibitor: semisynthesis of derivatives and preliminary structure-activity relationships. J Med Chem 2008, 51(20):6495-502.

27. McGowan E, Sanders S, Iwatsubo T, Takeuchi A, Saido T, Zehr C, Yu X, Uljon S, Wang R, Mann D, Dickson D, Duff K: Amyloid phenotype characterization of transgenic mice overexpressing both mutant amyloid precursor protein and mutant presenilin 1 transgenes. Neurobiol Dis 1999, 6:231-44.

28. Holcomb L, Gordon MN, McGowan E, Yu X, Benkovic S, Jantzen P, Wright K, Saad I, Mueller R, Morgan D, Sanders S, Zehr C, O'Campo K, Hardy J, Prada CM, Eckman C, Younkin S, Hsiao K, Duff K: Accelerated Alzheimertype phenotype in transgenic mice carrying both mutant amyloid precursor protein and presenilin 1 transgenes. Nat Med 1998, 4:97-100.

29. Zhou J, Fronseca MI, Kayed R, Hernandez I, Webster SD, Yazan O, Cribbs DH, Glabe CG, Tenner AJ: Novel A $\beta$ peptide immunogens modulate plaque pathology and inflammation in a murine model of Alzheimer's disease. J Neuroinflammation 2005, 2:28.

30. Hinz M, Broemer M, Arslan SC, Otto A, Mueller EC, Dettmer R, Scheidereit C: Signal responsiveness of IkappaB kinases is determined by $\mathrm{Cdc} 37$ assisted transient interaction with Hsp90. J Biol Chem 2007, 282(44):32311-9.

31. Zhang T, Li Y, Yu Y, Zou P, Jiang Y, Sun D: Characterization of celastrol to inhibit HSP90 and CDC37 interaction. J Biol Chem 2009, 284(51):35381-9.

32. Sreeramulu S, Gande SL, Göbel M, Schwalbe H: Molecular mechanism of inhibition of the human protein complex Hsp90-Cdc37, a kinome chaperone-cochaperone, by triterpene celastrol. Angew Chem Int Ed Engl 2009, 48(32):5853-5.

33. Li H, Zhang YY, Tan HW, Jia YF, Li D: Therapeutic effect of tripterine on adjuvant arthritis in rats. J Ethnopharmacol 2008, 18(3):479-84.

34. Allison AC, Cacabelos R, Lombardi VR, Alvarez XA, Vigo C: Celastrol, a potent antioxidant and anti-inflammatory drug, as a possible treatment for Alzheimer's disease. Prog Neuropsychopharmacol Biol Psychiatry 2001, 25(7):1341-57.
35. Kim Y, Kim K, Lee H, Han S, Lee YS, Choe J, Kim YM, Hahn JH, Ro JY, Jeoung D: Celastrol binds to ERK and inhibits FcepsilonRI signaling to exert an anti-allergic effect. Eur J Pharmacol 2009, 612(1-3):131-42.

36. Lee $\mathrm{JH}$, Koo $\mathrm{TH}$, Yoon $\mathrm{H}$, Jung $\mathrm{HS}$, Jin HZ, Lee $\mathrm{K}$, Hong $\mathrm{YS}$, Lee JJ: Inhibition of NF-kappa B activation through targeting I kappa B kinase by celastrol, a quinone methide triterpenoid. Biochem Pharmacol 2006, 72(10):1311-21.

37. Sassa $H$, Takaishi $Y$, Terada $H$ : The triterpene celastrol as a very potent inhibitor of lipid peroxidation in mitochondria. Biochem Biophys Res Commun 1990, 172(2):890-7.

38. Chavant F, Deguil J, Pain S, Ingrand I, Milin S, Fauconneau B, PéraultPochat MC, Lafay-Chebassier C: Imipramine, in part through tumor necrosis factor alpha inhibition, prevents cognitive decline and betaamyloid accumulation in a mouse model of Alzheimer's disease. $J$ Pharmacol Exp Ther 2010, 332(2):505-14.

39. Hickman SE, Allison EK, El Khoury J: Microglial dysfunction and defective beta-amyloid clearance pathways in aging Alzheimer's disease mice. J Neurosci 2008, 28(33):8354-60.

40. Volmar CH, Ait-Ghezala G, Frieling J, Weeks OI, Mullan MJ: CD40/CD40L interaction induces Abeta production and increases gamma-secretase activity independently of tumor necrosis factor receptor associated factor (TRAF) signaling. Exp Cell Res 2009, 315(13):2265-74.

doi:10.1186/1742-2094-7-17

Cite this article as: Paris et al:: Reduction of $\beta$-amyloid pathology by celastrol in a transgenic mouse model of Alzheimer's disease. Journal of Neuroinflammation 2010 7:17.

\section{Submit your next manuscript to BioMed Central and take full advantage of:}

- Convenient online submission

- Thorough peer review

- No space constraints or color figure charges

- Immediate publication on acceptance

- Inclusion in PubMed, CAS, Scopus and Google Scholar

- Research which is freely available for redistribution

Submit your manuscript at www.biomedcentral.com/submit
C) Biomed Central 